alcohol, resorcylidene anthranilic acid appears as yellow needles. No definit melting point was obtained; begins to change color at about $150^{\circ}$ with decomposition.

Calculated for $\mathrm{C}_{14} \mathrm{H}_{11} \mathrm{NO}_{4}: \mathrm{N}, 5.44$; found: $\mathrm{N}, 5 . \mathrm{Ir}$.

$x, 3$ - Dihydroxyphenylacetketodihydrobenzmetoxazine. - Treated on the water-bath as above described, resorcylidene anthranilic acid with acetic anhydride yields the oxazine. I,3-Dihydroxyphenylacetketodihydrobenzmetoxazine crystallized from methyl alcohol in colorless crystals. M. p. $192^{\circ}$.

Calculated for $\mathrm{C}_{16} \mathrm{H}_{18} \mathrm{NO}_{4}: \mathrm{N}, 4.68$; found: $\mathrm{N}, 4.63$.

p-Dimethylaminobenzylidene Anthranilic Acid.-In a cooled alcohol solution, molecular amounts of dimethylaminobenzaldehyde and anthranilic acid react with the formation of $p$-dimethylaminobenzylidene anthranilic acid. Bright red needles from alcohol. M. p. $176^{\circ}$.

Calculated for $\mathrm{C}_{28} \mathrm{H}_{18} \mathrm{~N}_{2} \mathrm{O}_{2}: \mathrm{N}$, 10.44; found: $\mathrm{N}$, 10.34.

p-Dimethylaminophenylacetketodihydrobenzmetoxazine.-With excess of acetic anhydride, $p$-dimethylaminobenzylidene yields the corresponding oxazine when heated on the water-bath. Dark yellow crystals from xylol. M. p. $162^{\circ}$.

Calculated for $\mathrm{C}_{1 \times} \mathrm{H}_{1 \times} \mathrm{N}_{2} \mathrm{O}_{3}: \mathrm{N}, 9.03$; found: $\mathrm{N}, 9.08$.

BOULDer, Colorapo.

\title{
THE DIRECT DETERMINATION OF OXYGEN IN ORGANIC COMPOUNDS.
}

By Matthand C. Boswell.

Received January 15, 1913.

Oxygen is one of the most frequently occurring constituents of organic compounds, and yet there is no direct method known for its quantitative determination. In the analysis of a compound the universal custom has been to determin the percentage of all the elements present with the exception of oxygen, subtract the sum of these from one hundred, and call the remainder the percentage of oxygen. Although this has presented no serious impediment to the development of organic chemistry, yet many instances have occurred in which a method for the quantitative estimation of oxygen would have been a great convenience. No doubt most organic chemists have in the course of their synthetic investigation work met with reactions involving considerable alteration in the oxygen content of a compound without changing to any appreciable extent the percentages of carbon and hydrogen present as, for instance, in the replacement of the amino group by hydroxyl. Moreover, a direct method for oxygen is also needed for its determination in commercial products as asphalt, rubber, etc., and for following the course of reactions involving the fixation of atmospheric oxygen in compounds. Several indirect 
methods have been worked out by Baumhauer, ${ }^{1}$ Ladenburg, ${ }^{2}$ Maumene, ${ }^{3}$ Mitscherlich, ${ }^{4}$ Persoz, ${ }^{5}$ Strohmeyer, ${ }^{6}$ Wanklyn and Frank, ${ }^{7}$ Cretier, ${ }^{8}$ and others. All of these suffer from the complications and consequent inaccuracies of indirect methods. None of them have come into general use, and many of them, such as the method of Mitscherlich, for the determination of $\mathrm{C}, \mathrm{H}, \mathrm{O}, \mathrm{N}, \mathrm{Cl}, \mathrm{Br}, \mathrm{I}$ and $\mathrm{S}$ in one operation, have probably not been performed since the original experiments by the investigators themselves.

The method described in this paper consists in the determination of the amounts of water, carbon dioxide and carbon monoxide formed when a weighed amount of substance is heated in a quartz tube to a high temperature in a current of pure hydrogen, the products of the reaction being passed over a long layer of charcoal particles heated to a white heat. In the presence of the two strong reducing agents, hydrogen and carbon, at a high temperature, all the oxygen in the original compound is converted into the simple compounds, water, carbon dioxide and carbon monoxide. The hot carbon also reacts with the water, forming carbon monoxide and hydrogen, and likewise reduces some of the carbon dioxide to monoxide. However, not only are both of these reactions reversible, but in the passage of the gaseous mixture through the hot tube they probably do not reach equilibrium. Hence water and carbon dioxide are always observed among the reaction products. The water is absorbed in concentrated sulfuric acid, the carbon dioxide in soda-lime and the carbon monoxide determined by a modification of the method of Levy, ${ }^{9}$ which consists in passing the gas from which the water and carbon dioxide have been removed through iodine pentoxide and the determination of the carbon dioxide formed in the oxidation by absorption in soda lime.

Description of Apparatus. $-A$ is a quartz tube $\mathrm{r} 3 \mathrm{~mm}$. in internal diameter and $980 \mathrm{~mm}$. in length. Commencing $135 \mathrm{~mm}$. from one end a layer of charcoal particles about $\mathrm{I} \mathrm{cmm}$. in size, free from powdered charcoal, is packed tightly in the tube for the length of $400 \mathrm{~mm}$. and held in place by asbestos plugs at each end. This tube is set in a "combustion furnace" of the usual form, except that the iron trough and tiling supporting the combustion tube are omitted, and the iron work supporting the

${ }^{1}$ Ann., 90, 228 (1854); Jahresb., I855, 768; Z. anal. Chem., 5, 14I (1866).

${ }^{2} A n n .$, I35, I (1865).

${ }^{3} J$. prakt. Chem., 84, 185 (1861); Compt. rend., 55, 432 (1861).

- Pogg. Ann., 130, 536 (184I); Z. anal. Chem., 6, 136 (1867); Ber., I, 45 (I868); Ibid., 6, I000 (1873); Ibid., 7, I527 (1874); Z. anal. Chem., 7, 272 (1868); Ibid., 15, 371 (I876).

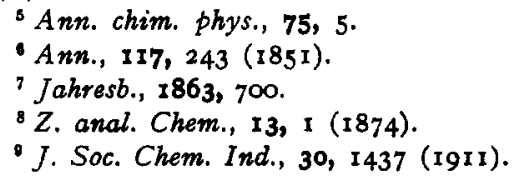


trough also, if possible, removed so as to avoid any transfer of heat to the substance during the preliminary heating of the charcoal. Two asbestos board protectors, $a, b$, are cut so as to fit tightly across the furnace, one I $5 \mathrm{~mm}$. from the end of the charcoal layer, and the second $30 \mathrm{~mm}$. from the first. If these are cut so as to fit tightly around the quartz tube and

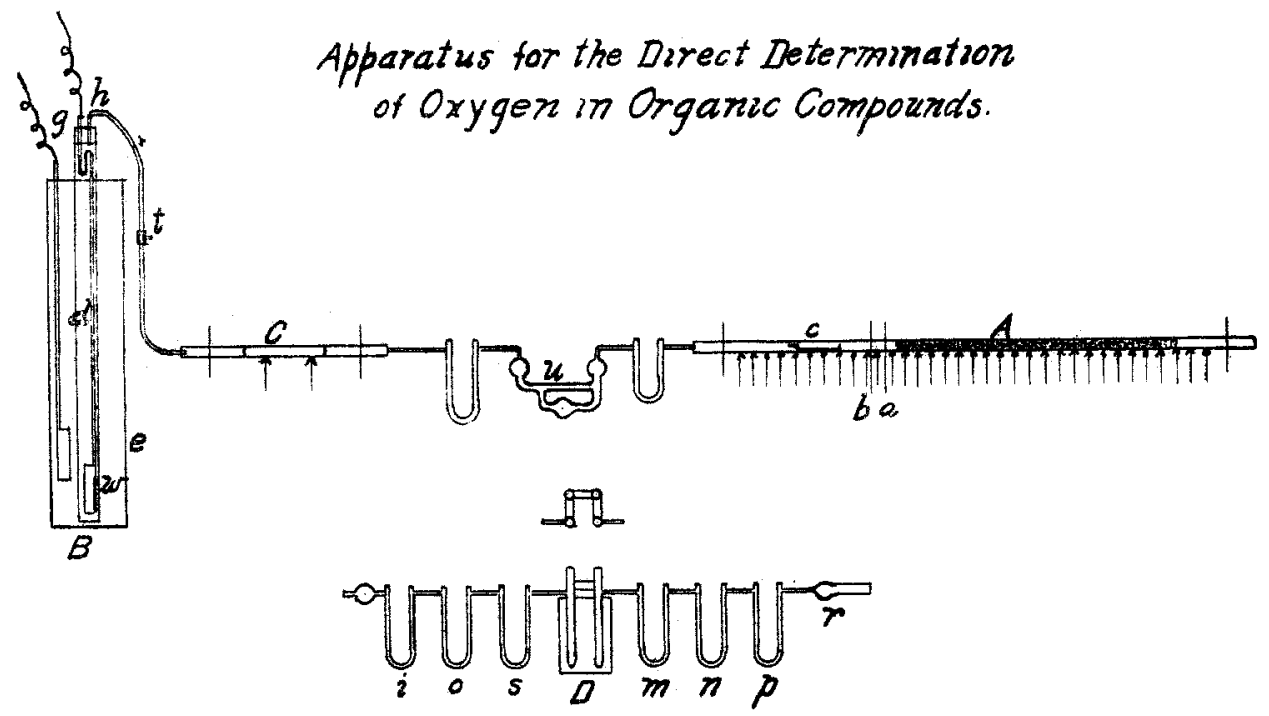

along the sides of the furnace it is possible to heat the entire charcoal layer to a white heat in a rapid current of hydrogen and thus clear the tube of all free oxygen and oxygen compounds, without warming in the least the silica boat $c$ containing the weighed amount of substance, which rests $60 \mathrm{~mm}$. from the nearer asbestos protector. The remainder of the tube $A$ is empty.

The Hydrogen Generator.-The hydrogen is produced electrolytically in the generator $B$. This consists of a heavy outer glass vessel, $e, 600$ $\mathrm{mm}$. in height and $\mathrm{r} 30 \mathrm{~mm}$. in diameter, containing dilute sulfuric acid ( $\mathrm{x}: 6$ ) and having an inner glass tube, $d, 690 \mathrm{~mm}$. in length and $35 \mathrm{~mm}$. in diameter, open at the lower end and reaching almost to the bottom of the containing vessel. Both electrodes are of heavy lead, the anode being in the outer vessel and raised $60 \mathrm{~mm}$. from the lower end of the inner vessel containing the cathode $w$. The cathode tube is closed by a rubber stopper with two holes, through one of which passes a bent glass tube, $h$, to conduct away the hydrogen, and through the second passes the $U$ tube $g$, full of mercury and carrying the insulated conductor to the cathode. A current of cold water is made to circulate through a lead tube wound around the cathode vessel. This generator is connected up with a lamp rheostat and an ammeter to the street current of 1 ro volts. The hydrogen so generated contains an appreciable amount of oxygen which is re- 
moved by passing the gas through a quartz tube, $C, 360 \mathrm{~mm}$. in length and I $3 \mathrm{~mm}$. internal diameter, containing a tightly wound coil of copper gauze $130 \mathrm{~mm}$. in length, which is heated to white heat in a small furnace of two flat, wide flames. The hydrogen from this passes first through a $U$ tube containing calcium chloride, then through a sulfuric acid drier, $u$, of special form, ${ }^{1}$ which causes very thorough contact of gas with acid with very smail friction and pressure head, and finally though a $U$ tube containing phosphorus pentoxide from whence it passes into the main tube $A$.

Absorption Apparatus. -This consists of three parts-that for the absorption of water, that for the absorption of carbon dioxide, and that for the oxidation of carbon monoxide to dioxide and absorption of the dioxide thus formed. For the reasons given by Benedict, ${ }^{2}$ it is advisable to use concentrated sulfuric acid on pumice for the first absorption. An ordinary calcium chloride $U$ tube, $i$, with a bulb, is filled with small pieces of pumice about I cmm. in size and so much concentrated sulfuric acid is run in that a seal is just made at the bend, after impregnating the pumice. The carbon dioxide is preferably absorbed by moist soda lime made by the method of Benedict ${ }^{2}$ and cut into pieces about I cmm. in size and held between asbestos plugs in a $U$ tube with limbs $120 \mathrm{~mm}$. long and I I $\mathrm{mm}$. in diameter. A U tube, $s$, of pumice moistened with concentrated sulfuric acid, follows to retain the moisture carried over from the soda lime. The method of determining the carbon monoxide is a modification of that devised by Levy. The iodine pentoxide apparatus $D$, shown in elevation and plan in the figure, consists of two $U$ tubes $14 \mathrm{~mm}$. in diameter joined together on one side about $\mathrm{I}$ ro $\mathrm{mm}$. from the bottom by a tube of about the same diameter. One $U$ tube is filled with rolls of copper gauze, the other is filled with iodine pentoxide on asbestos made by impregnating enough asbestos to fill the tube with a solution of 25 to 30 grams of iodine pentoxide or iodic acid in water, evaporating to dryness on the water-bath and heating in a vacuum at $250^{\circ}$ for several hours. The ends of the $U$ tubes are then carefully sealed and the entrance and exit tubes carefully stoppered when not in use. During the analysis this is heated in an oil-bath at $160-170^{\circ}$ and connected with the tube $s$. The carbon monoxide is oxidized to dioxide completely, while the methane, ethane and hydrogen are unacted on, provided the gas is dry and no ethylene or acetylene hydrocarbons are present. The iodine liberated condenses for the most part in the wide connecting tube, the last traces being removed by the copper. As it is very difficult to completely free iodine pentoxide from iodic acid ${ }^{3}$ provision must be made for removing the moisture liberated when any iodic acid is reduced by the carbon monoxide. This is

${ }^{1}$ Trans. Faraday Soc., 6, Io (Igro).

2 Am. Chem. J., 23, 323 (1900).

${ }^{3}$ Compt. rend., 153, 1226-9; C. A., 6, 721 . 
effected by a $U$ tube, $m$, containing sulfuric acid on pumice. The gas is then led into a $U$ tube, $n$, containing soda lime similar to tube $o$, and this is followed by a $U$ tube, $p$, of sulfuric acid on pumice similar to $s$. The absorption train is completed by a straight calcium chloride tube, $r$, to prevent absorption of moisture from the air.

Method of Conducting the Analysis.-Approximately three-tenths of a gram of substance is carefully weighed out in a silica boat which has been cleaned, heated in the blast flame, and cooled in a desiccator. The five absorption vessels are weighed, care being taken to rub each vessel to constant weight with clean dry cheese-cloth. The necessity for this must be emphasized because the analysis involves ten separate weighings. The boat containing the substance is now inserted in the tube $A$, care being taken that it is not closer than $60 \mathrm{~mm}$. from the nearer asbestos. board $b$. The hydrogen apparatus is connected to the tube by means of a rubber stopper and the apparatus tested for any leak under the full head. of acid in the generator $B$. The flames under $C$ are now lighted and when the quartz tube is glowing under the entire portion holding the copper gauze, the hydrogen is allowed to pass in a very rapid stream by regulating the screw pinchcock $t$. In a couple of minutes the burners extending from the asbestos board $a$ to the end of the furnace are lighted and turne full on. In three or four minutes this part of the tube is glowing. The rapid current of hydrogen is continued for four or five minutes longer. The rate is then considerably diminished and the absorption tubes connected by means of a tightly fitting rubber stopper. The remainder of the absorption apparatus is then connected in the order described above, and the temperature of the oil-bath $D$ raised to $165^{-1} 7^{\circ}$. The rate of hydrogen is now still further diminished so that there is an actual but very small movement of gas through the apparatus. The burners at the other end of the furnace are now lighted, and very gradually the substance is warmed and finally heated with the full flames. The hydrogen. current is continued for 15 minutes after this, the rate being somewhat increased during the last ten minutes in order to drive over all the gaseous products of the reaction. The success of the determination depends largely on the very gradual heating of the substance. The heating of the tube from the first lighting of the flames under the charcoal till the complete sweeping over of the reaction products requires about $I / 2$ to $\mathrm{I}^{3 / 4}$ hours. The absorption apparatus is then detached from the apparatus $D$ and the tube $m$, and dry air free from carbon dioxide passed through the five vessels for ten minutes. The tubes are then detached, allowed to remain in the balance room for an hour, observing the usual precautions, and weighed, care being taken to wipe each to constant weight.

Results.-In calculating the amount of oxygen in the substance from the increase of weight of the absorption vessels, it must be borne in mind. 
that although the increase in the tubes $n$ and $p$ following the iodine pentoxide apparatus represents the weight of carbon dioxide absorbed, yet one-half of the oxygen present in this carbon dioxide has come from the iodine pentoxide and not from the substance. The substances analyzed were thoroughly purified by repeated crystallizations of each from two solvents and where possible by sublimation. The purity was verified in some cases by constancy of melting point, and where this was incapable of determination, by an analysis of the compound for carbon and hydrogen.

\begin{tabular}{|c|c|c|c|c|c|}
\hline Substance. & 1. & 2. & 3. & 4. & 5. \\
\hline Cane sugar... & 0.3020 & 0.0775 & 0.0700 & 0.1008 & 0.0689 \\
\hline Succinic acid........... & 0.2864 & 0.0532 & 0.0606 & o. 1772 & 0.0473 \\
\hline Dimethyl oxalate... . . . . & 0.2978 & 0.0292 & 0.0477 & $0.275^{2}$ & 0.0259 \\
\hline Phthalic anhydride., & 0.3024 & 0.0262 & 0.0187 & $0.172 \mathrm{I}$ & 0.0233 \\
\hline \multirow[t]{2}{*}{ 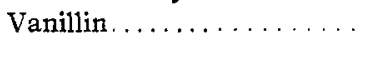 } & 0.2893 & 0.0 .132 & 0.0100 & 0.2015 & 0.0117 \\
\hline & 6. & 7. & 8. & 9. & 10. \\
\hline Cane sugar. . & 0.0509 & 0.0366 & 0.1564 & 51.8 & 51.5 \\
\hline Succinic acid.... & $0.044 \mathrm{I}$ & 0.0644 & o. 1558 & 54.4 & $54 \cdot 2$ \\
\hline Dimethyl oxalate........ & 0.0347 & 0.1001 & 0.1607 & 54.0 & 54.2 \\
\hline Phthalic anhydride ....... & 0.0136 & 0.0626 & 0.0995 & 32.9 & 32.4 \\
\hline Vanillin............... & 0.0073 & 0.0733 & 0.0923 & 31.9 & $3 I .6$ \\
\hline
\end{tabular}

Column I gives the weight in grams of substance taken.

Column 2 gives the weight in grams of water formed.

Column 3 gives the weight in grams of carbon dioxide formed.

Column 4 gives the weight in grams of carbon dioxide formed by oxidation of monoxide.

Column 5 gives the weight in grams of oxygen corresponding to the water in column 2.

Collumn 6 gives the weight in grams of oxygen corresponding to the carbon dioxide in column 3 .

Column 7 gives the weight in grams of oxygen corresponding to the carbon dioxide in column 4 .

Column 8 gives the weight in grams of total oxygen, the sum of columns 5,6 and 7 .

Column 9 gives the percentage of oxygen found.

Column ro gives the percentage of oxygen calculated from the formula.

It is seen on comparison of the oxygen percentages calculated from the formulas with the percentages actually found, as shown in columns 9 and IO, that the method is capable of about the same degree of accuracy as the combustion method for determining carbon and hydrogen, when this latter is carefully conducted. This is considerably better than at first sight would seem possible, judging from the nature of the process. It might reasonably be expected that even though all the oxygen of the compound analyzed should appear in the reaction product in the form of water, carbon dioxide and carbon monoxide, stable compounds of carbon and hydrogen might be formed which might partly condense in the absorption apparatus and thus vitiate the result. It would be very surprising if in the application of this method to a great variety of com- 
pounds, some cases of this kind are not encountered. However, under the conditions of the determinations as described above (the very slow distillation over the very long and very hot carbon layer in a current of hydrogen) this objection does not apply, at least, to the compounds analyzed and these are fairly representative. Should this objection, however, in any case be observed, it could very probably be eliminated by the use of a small weighed amount of a pure oxidizing agent of definit oxygen content, as potassium permanganate, intimately mixed with the substance in the boat.

It is the intention to proceed in this laboratory with the investigations of this or other means of obviating this possible source of error, and also with the application of the method to compounds containing nitrogen and other elements.

TNIVERSITY OF TORONTO.

[HaRriman Research Laboratory, RoOsevelt Hospital, New York CtTy, N. Y.]

NEPHELOMETRY IN THE STUDY OF PROTEASES. II.

By Peirip Adolph KoBer.

Received January 21, 1913.

Introduction. - In a previous paper ${ }^{1}$ a method was described for studying proteases and nucleases, based on the precipitation of the substrate as a suspensoid by a suitable precipitant, and the determination of this suspended substance with a nephelometer. Figures were given to show that by using a $12 \%$ solution of sodium chloride as a precipitant, quantitative results were obtained with $0.0005 \%$ to $0.005 \%$ edestin solutions. ${ }^{2}$ The object of this paper is to show that by using the precipitant given below, equal accuracy can be obtained with casein, thus giving us extremely sensitive methods for peptic, tryptic and ereptic digestion.

General Considerations. - In choosing edestin and casein as substrates. the following points were considered: (I) For the accurate standardization of these enzymes, it is essential not only to have sensitive instruments to measure the rate of digestion, but also to have a substance that is easily digested by these ferments, so that the measurement of the activity, like other speed estimations, will occupy as little time as possible. The object in view, of course, is to be able to determin the activity at any instant. (2) Not only are casein and edestin digested easily by most ferments but they may be useful in distinguishing trypsin from erepsin. Fischer and Abderhalden ${ }^{3}$ showed that trypsin digested not only casein but proteins like edestin as well. Dox, ${ }^{4}$ on the other hand, seems to have

${ }^{1}$ Kober, J. Biol. Chem., 13, 485 (1913).

${ }^{2}$ This represents the range over which the best nephelometric work can be done.

${ }^{3}$ Fischer and Abderhalden, Z. Physiol. Chem, 60, 81 (1903).

' Dox, J. Biol. Chem., 6, 437 (1906). 